\title{
Fenomenologia: 0 uso como método em Comunicação
}

Monica Martinez e Paulo Celso Silva

\section{Resumo}

Em áreas do conhecimento como a filosofia, a fenomenologia é compreendida como uma proposta teórica. No âmbito da comunidade científica da Comunicação, no entanto, não há este consenso: a fenomenologia tanto é entendida como uma teoria quanto, mais comumente nos últimos anos, como um método. A questão é que esta ambiguidade pode resultar numa certa fluidez do emprego da abordagem, uma vez que a ausência de uma proposta mais bem definida pode levar ao questionamento dos resultados dos estudos que a empregam como método. Neste contexto, este artigo tem como objetivo discutir esta temática, fazendo um breve levantamento histórico sobre a fenomenologia, debatendo esta relação teóricometódica, e sugerindo uma proposta de sete passos para 0 método fenomenológico. Finalmente, esta proposta é usada como uma chave para se analisar estudo feito com este método, cujo resultado revela que a explicitação das técnicas empregadas (como entrevista aprofundada e observação participante) poderia melhorar a compreensão do método na comunidade científica da área de Comunicação.

\section{Palavras-Chave}

Comunicação. Fenomenologia. Teoria. Metodogia.

Monica Martinez I martinez.monica@uol.com.br Doutora pela Escola de Comunicação e artes da Universidade de São Paulo (USP), com pós-doutorado pela Universidade Metodista de São Paulo (UMESP) e estagio pós-doutoral pela Universidade do Texas. Docente do Programa de Comunicação e Cultura da Uniso (SP).

Paulo Celso Silva | paulo.silva@prof.uniso.br Doutor pela Universidade de São Paulo (USP), com pós-doutorado pela Universidade de Barcelona (ES). Docente do Programa de Comunicação e Cultura da Uniso (SP).

\section{Introdução}

Quase um século após ter sido idealizada pelo filósofo alemão Edmund Husserl (18591938), a fenomenologia ainda faria sentido nos estudos em Comunicação contemporâneos? Esta abordagem filosófica que compreende que o mundo está ali, antes da reflexão e do julgamento humanos, demandando, portanto, neutralidade do pesquisador para descrever a experiência, sem sobrepor suas referências, crenças e seus valores, poderia ser usada como método em Comunicação hoje? Para tentar responder estas questões, este artigo expõe uma síntese dos antecedentes filosóficos da fenomenologia a partir de três autores, procede à revisão de literatura sobre a fenomenologia como método, apresenta uma proposta metodológica e, finalmente, analisa uma pesquisa recente feita com o uso do método.

Dentre as teorias sobre a percepção fenomenológica concebidas por filósofos, destacamos três que serão apresentadas a seguir. 


\subsection{Edmund Husserl (1859-1938): o filósofo alemão fundador da fenomenologia}

A crise do subjetivismo e do irracionalismo no pensamento ocidental é uma das marcas dos debates no início do século XX, época em que a psicologia também começa a se desenvolver como ciência. É nesse contexto de reflexão sobre o conhecimento que surge a fenomenologia de Edmund Husserl como um método para alcançar o conhecimento do conhecimento. Segundo ele, é necessário por entre parêntesis tudo o que fora construído e aceitar o que é dado à consciência, ou seja, o fenômeno, a partir da própria coisa percebida, sem relação ao eu que a pensa (ao que denominou de epoché fenomenológica transcedental). ${ }^{1}$ É um momento crítico para a ciência e sua necessidade de explicações e justificativas, mas, ao mesmo tempo, é uma abordagem rigorosamente científica, pois permitiria que a própria coisa ( o fenômeno) se apresente aos sentidos. Husserl afirma a fenomenologia como lógica fundamental, no sentido que a manifestação do fenômeno é dada pela experiência.

Do autor alemão, destacam-se duas obras essenciais para nossa abordagem: Investigações filosóficas (1901-1902) - da fase logicista - e Ideias diretrizes para uma pura fenomenologia e uma filosofia fenomenológica (1913) - da fase transcendentalista. Pode-se considerar uma terceira fase, a pós-transcendental, composta por obras como A crise das ciências européias e a fenomenologia transcendental (1936), onde desenvolve o conceito de mundo-da-vida (Lebensvelt), um mundo da experiência, do a priori, pré-científico, visto que a ciência também é resultado de especulações e experiências:

Na atitude fenomenológica trata-se de [...] ocupar-nos exclusivamente com o próprio mundo da vida, ou seja, como tem lugar para nós a permanente consciência da existência universal, do horizonte universal de objetos reais, efetivamente existentes. 0 objeto da investigação fenomenológica sobre 0 mundo não é tanto 0 ser do mundo quanto seu sentido. 0 interesse teórico da atitude fenomenológica dirige-se exclusivamente ao universo da subjetividade no qual se nos dá o mundo como existente (HUSSERL, 2002, p. 33).

A filosofia de Husserl ocupa-se da essência e da existência do ser, sempre questionando o significado do que o objeto seja, e de como é possível o objeto exista para 0 observador. Para responder tais perguntas, Husserl assume quatro passos metodológicos. 0 primeiro é a desnaturalização da consciência. A consciência é considerada sempre de alguma coisa e ocorre graças ao transcendente (o mundo interior). Isso implica aceitar que a consciência de é anterior à noção de sujeito-objeto e origina o ser, portanto é absoluta. Se para Descartes o eu penso era 0 começo de todo conhecimento, para Husserl 0 eu penso é sobre algo existente, pois os objetos estão em relação com meu pensar. 0 segundo 
passo é a intencionalidade ou a essência da consciência, visto que é anterior e a transcende, pois a intencionalidade aponta a consciência para si. A intuição, como terceiro passo, evidencia 0 objeto, e, finalmente, a generalização da noção de objeto compreende, além da materialidade destes, as essências, os objetos ideais e as formas de categorias. Depreende-se disso que a fenomenologia busca as essências por meio da redução eidética - quando os fenômenos são transformados em essências, o mundo é o meio para o eu, não o interior, porém o existente.

A teoria de Husserl não esteve isenta de críticas, como é o caso da elaborada pelo filósofo marxista francês Henry Lefebvre (1901-1991) em 1946. Segundo ele, na fenomenologia de Husserl nenhuma contradição é resolvida, mas negada pela descrição das "[...] totalidades dadas imediatamente pela consciência [...] a contradição pertence a aparência, ao erro" (LEFEBVRE, 1948, p. 175). Isso para Lefebvre implica em uma posição escolástica moderna, o retorno ao absolutismo, o maior dogma dos metafísicos.

De acordo com Lefebvre (1948, p. 183), "logo depois de ter 'reduzido', 'suspendido' e 'posto entre parenteses' tudo, o que nos sobra?

Chegamos ao 'Eu' do filósofo, ao eu vazio, maravilhosamente transparente e purificado pela [...] separação do mundo. E esse eu filosófico recebe o magnífico nome de "transcendental". Para Lefebvre (1948), o racionalismo proposto pelo alemão não resolveu a crise do racionalismo abstrato. Aliás, ele crê que se trate de um retrocesso no pensamento filosófico, pois elimina a história e a ciência em troca de verdades absolutas e eternas.

Em 1938, ano da morte de Husserl (2002, p. 10) e já com o Nazismo no comando da Alemanha, "[...] o franciscano Hermann Leo van Breda (19111974) transportou clandestinamente cerca de 40.000 páginas de manuscritos estenografados [...] e inéditos de Husserl" à Universidade Católica de Lovain, na Bélgica, desde então um centro de estudos da obra do pensador.

Antes de ser um método próprio com rigor radical do conhecimento, a fenomenologia desenvolvida por Husserl (2002, p. 9) é "uma atitude e uma postura filosófica" que influenciará pensadores como o filósofo alemão Martin Heidegger (18891976), discípulo de Husserl que postula suas próprias ideias filosóficas sobre a intencionalidade e o significado da fenomenologia que, para ele, era um conceito de método. Na França, os dois expoentes principais são os filósofos Jean-Paul Sartre (1905-1980) e Maurice Merleau-Ponty (1908-1961). 0 primeiro declara a subjetividade como ponto de partida da filosofia existencialista, desenvolvida - e militada - pelo segundo.

\subsection{Maurice Merleau-Ponty (1908-1961): a fenomenologia da existência}

0 filósofo francês Maurice Merleau-Ponty desenvolve a relação e articulação entre a 
fenomenologia e a existência. No prefácio de

Fenomenologia da percepção (1945), ele afirma

que a fenomenologia "[...]é 0 estudo das essências, e todos os problemas, segundo ela, resumem-se em definir essências... Mas a fenomenologia é também uma filosofia que repõe as essências na existência" (MERLEAU-PONTY, 1999, p. 1). Ainda no prefácio, indica a fenomenologia como um método: "[...] a fenomenologia só é acessível a um método fenomenológico... Trata-se de descrever, não de explicar nem de analisar... A ciência não tem e não terá jamais o mesmo sentido de ser que 0 mundo percebido" (MERLEAU-PONTY, 1999, p. 2).

Merleau-Ponty chamava Husserl de mestre. Segundo ele, as obras finais de Husserl - que caminham para o existencialismo filosófico explicam as iniciais. Ponty assume a redução fenomenológica, mas essa não conduz ao eu puro e sim ao sujeito que está no mundo, vivenciando-o para daí tirar o seu sentido. Dessa forma, o mundo da vida é o ponto alto da filosofia fenomenológica proposta por Ponty, que o levará ao método.

No tocante ao método fenomenológico ele afirmará a positividade do método eidético, fundando 0 possível e o real. É a intencionalidade da qual falava Husserl, indicando que a consciência é consciência para alguma coisa do e no mundo, que está posta, vivida e dada antes do conhecimento. A consciência é um 'projeto do mundo', o qual ela não possui, mas para o qual sempre está se dirigindo (1999, p. 15). Dessa maneira temos a intencionalidade, enquanto abertura para o mundo da vida e a intersubjetividade, abertura para os outros e um colocar frente às outras consciências.

Outra noção importante em Merleau-Ponty (1999, p. 18) é a de aliar a historicidade e sentido.

"Porque estamos no mundo, estamos condenados ao sentido, e não podemos fazer nada nem dizer nada que não adquira um nome na história" (1999, p. 18). À diferença de Husserl, para quem a compreensão do significado é encontrada por meio da descrição que quer alcançar a essência, a postura metodológica de Merleau-Ponty está atrelada ao mundo, a uma compreensão mundana e crítica. Para Ponty (1999, p. 20), a fenomenologia, enquanto revelação do mundo, "[...] repousa sobre si mesma, ou, ainda, funda-se a si mesma. Todos os acontecimentos apoiamse em um 'solo' de postulados e, finalmente, em nossa comunicação com o mundo como primeiro estabelecimento da racionalidade".

A influência de Merleau-Ponty nos estudos contemporâneos pode ser verificada entre os pesquisadores que tomam o corpo como referencial investigativo, onde este é, ao mesmo tempo e sem contradição, biológico e fenomênico.

\subsection{Vilém Flusser (1920-1991): a ponte com a comunicação do filósofo tcheco-brasileiro}

Nascido em Praga em 1920, Flusser não chegou a concluir seus estudos de Filosofia. Aos 19 anos, devido à chegada das tropas nazistas, 
abandona o seu país rumo a Londres. Em 1940, já estabelecido no ramo comercial em São Paulo, dedica-se aos estudos de maneira autodidata. Foi professor na Escola Politécnica da Universidade de São Paulo e um dos fundadores do Curso de Comunicação Social na FAAP (Fundação Armando Álvares Penteado). De grande atividade intelectual, na Alemanha colabora com o jornal Frankfurter Allgemeine Zeitung e, no Brasil, com O Estado de S. Paulo, a Folha de S. Paulo e a Revista Brasileira de Filosofia. Nos primeiros anos da década de 1970, retorna à Europa período considerado o de seu maior prestígio internacional. Fixa-se na França onde permanece até 1992, quando falece num acidente de carro na volta de uma palestra em sua cidade natal.

Sua postura fenomenológica está expressa na obra Brasil ou a procura de um novo homem: por uma fenomenologia do subdesenvolvimento - a que chama de método. No livro, ele busca compreender o homem brasileiro a partir de um distanciamento para evitar que preconceitos e juízos de valor obscureçam o estudo. 0 primeiro passo é ontológico, ou seja, responder que e qual Flusser distancia-se do ser brasileiro, caso ele exista em ato ou em potência. 0 Flusser escolhido é o imigrante europeu. Para tanto, a descrição do brasileiro e do país faz-se necessária e obrigatória. Contudo, como ele indica: "A meta é fornecer uma imagem, a qual, graças à analogia e contraste, possa servir de orientação ao ocidental em geral, e em particular ao burguês intelectual do Ocidente" (FLUSSER,
1998, p. 33) Mais adiante, considera necessário diferenciar meta de método. A primeira referese ao falar sobre as coisas que ainda não se fizeram, usando a técnica sotto voce (ir diminuindo 0 volume da voz para enfatizar). Já no método deve-se permitir a articulação das coisas sem nada prévio, para que as coisas não comprovem ou sustentem hipóteses e teses (FLUSSER, 1999, p. 38).

Ao discorrer sobre as ficções, Flusser utiliza uma mesa para exemplificar o método fenomenológico. Em uma primeira impressão, a mesa pode ser compreendida como ficção da realidade dos sentidos. Visto de outra maneira, ela seria considerada um campo eletromagnético e gravitacional vazio. Em ambas as situações, a mesa é uma ficção e sua realidade estaria na soma de todas essas ficções e/ou pontos de vista. "Se pusermos todos eles entre parênteses e procurarmos contemplar a essência mesma da mesa? Que resta? A fenomenologia responde a esta pergunta: 'resta a pura intencionalidade'. Mas que significa isto? A rigor: "nada resta"” (FLUSSER, 1966).

Ele também se interessa pela fenomenologia da fotografia, que é desenvolvida no livro Filosofia da caixa preta. Diríamos que se trata da fenomenologia da mídia e da linguagem por meio da fotografia, os quais são retomados depois em seu livro Les Gestes (1999). Nele as atividades humanas são descritas como gestos. Contudo, os gestos são também técnicos e tecnológicos, como 
fotografar. Por meio da gestualidade, em sentido muito ampliado, o mundo se revela ao homem: "A análise dos gestos nos mostra que existir e ser livre são sinônimos no sentido de significar. Um gesto é livre, e não um movimento condicionado, quando ele significa uma relação intersubjetiva" (FLUSSER, 1999 apud ARANTES, 2009, p. 3).

\section{A influência de Vilém Flusser no Brasil e no} exterior é grande. Basta uma pesquisa com seu nome em mecanismos de busca para encontrar textos que transitam pela filosofia, comunicação, psicanálise, geografia e educação, entre várias áreas do conhecimento.

\section{Observações sobre o método fenomenológico}

Para o sociólogo Antonio Carlos Gil, docente dos Programas de Mestrado e Doutorado em Administração da Universidade Municipal de São Caetano do Sul (USCS/SP), os métodos se dividem em dois troncos-chave. De um lado, os que oferecem bases lógicas para a investigação científica, mais abstratos e, em geral, norteados por propostas filosóficas. Do outro, os métodos que abrangem os procedimentos técnicos a serem utilizados (GIL, 1999, p. 26-27). Neste contexto, o método fenomenológico, relacionado à fenomenologia, se enquadraria no primeiro grupo, que compreenderia o método dedutivo - relacionado ao racionalismo -, 0 indutivo - ao empirismo -, o hipotético-dedutivo - ao neopositivismo -, o dialético - ao materialismo - (GIL, 1999, p. 27).
Em alinhamento com suas bases filosóficas, 0 método fenomenológico consistiria em "[...] mostrar o que é dado e em esclarecer este dado. Não explica mediante leis, nem deduz a partir de princípios, mas considera imediatamente 0 que está presente à consciência, o objeto" (GIL, 1999, p. 32). Norteado pela fenomenologia, o método não se preocupa com as raízes ou os bastidores do fenômeno, nem se baseia numa única verdade. Não se preocupa, igualmente, com sua dimensão histórica.

Esta dimensão a-histórica do estudo fenomenológico, precisamente, tem servido muitas vezes para 0 ataque dos adversários [...], convictos de que muitos problemas destas nações têm as suas explicações, as suas raízes, nas características de seu desenvolvimento social, econômico e cultural. (TRIVIÑOS, 1987, p. 4).

Também não se preocupa com a compreensão dos aspectos subjetivos do observador nem com os aspectos objetivos da realidade. Isto porque o "[...] dado absoluto não é a vivência que eu tenho como ser humano." (TRIVIÑOS, 1987, p. 44). Para o método fenomenológico, a vivência singular é universalizada: pesquisadores e leitores da pesquisa podem compreendê-la porque são também participantes da condição humana. 0 que se busca, portanto, é uma descrição direta, intuitiva, da experiência baseada na observação, ainda assim sabendo que ela permite várias interpretações. Como diz Gil (1999, p. 32), "[...] haja o que houver, a coisa está aí”.

0 sociólogo Pedro Demo (1995, p. 250), professor aposentado da Universidade de Brasília, classifica a 
fenomenologia como um método alternativo, "[...]que prima pela modéstia do respeito à realidade social" (DEM0, 1995, p. 250). Segundo Demo (1995, p. 250), a fenomenologia, em "vez de partir de métodos prévios, dentro dos quais se ensaca a realidade, faz o caminho contrário". E qual caminho seria este? Para ele, primeiro tentar compreender a realidade social em sua intimidade, que reconhece como algo existencial, irredutível à realidade natural.

0 sociólogo ressalta que o método fenomenológico tem 0 foco "[...] sobre o que é mundano, corriqueiro e aceito sem exames, em oposição ao que é raro, irregular, controverso ou intrigante." (DEMO, 1995, p. 251). Neste sentido, tanto acolheria áreas negligenciadas pelas ciências sociais, quanto teria o poder de retirar do pedestal 0 cientista social, que ao se julgar parte de uma elite - protegido por uma redoma lógico-analítica - estaria perdendo o vínculo com a vida real. (DEM0, 1995).

\subsection{A importância da escolha das técnicas}

Os métodos são complementados pelas técnicas, que seriam "[...] o lugar da construção dos dados ou do objeto empírico. Compreende os procedimentos de coleta de informações e das transformações destas em dados pertinentes à problemática geral. Será em função desses dados que se elaborará o objeto científico." (LOPES, 2003, p. 128). Cabe ressaltar que às vezes é difícil delimitar o que é método é o que é técnica, tratando-se de uma interface sutil.

\subsection{Proposta para o uso da fenomenologia como método em Comunicação}

Nos dedicamos agora a sugerir uma certa sequência de ações possíveis para nortear uma pesquisa que empregue o método fenomenológico:

\subsubsection{Primeiro passo: a revisão de literatura}

No caso brasileiro, a disponibilização das pesquisas em sistema de acesso livre e gratuito facilita a revisão de literatura pelo pesquisador. A leitura e fichamento apropriados são fundamentais.

\subsubsection{Segundo passo: a descrição dos procedimentos metodológicos}

Uma vez que o método fenomenológico é aberto, o ideal é adotar técnicas de pesquisa que assegurem a validação científica da coleta. Destacamos três exemplos:

a) Entrevista aprofundada: numa tentativa de promover o diálogo com o outro (MEDINA, 1990), por meio da escuta atenta e ativa (AMÉLIO; MARTINEZ, 2005), sem a intenção de endossar (KRAMER, 1995), tampouco de arguir, mas de compreender (KÜNSCH, 2009; LIMA, 2009) os nexos e os sentidos a partir do ponto de vista do entrevistado.

b) História de vida: em Comunicação tende a 
ser entendida como uma técnica que permite registrar fragmentos panorâmicos, como se fossem fotografias de um dado instante espaço-temporal (como no perfil jornalístico) ou a integralidade mais ampla da vida (caso de biografias) de indivíduos ou grupos sociais. Pode ter características específicas, como a Jornada do Herói (MARTINEZ, 2008).

\section{c) Observação participante: a docente do} Programa de Pós-Graduação em Comunicação da Universidade Metodista de São Paulo (Umesp) Cicília Peruzzo (2005, p. 125, grifo do autor), lembra que a técnica "[...] consiste na inserção do pesquisador no ambiente natural da ocorrência do fenômeno e de sua interação com a situação investigada".

\subsubsection{Terceiro passo: a entrada no campo e a seleção das fontes}

Como o método fenomenológico busca descrever a experiência de forma direta, as condições e exigências para a entrada no grupo ou universo a serem observados devem ser observadas. Em culturas como a brasileira, 0 acesso pode ser facilitado por conhecidos que façam parte daquele sistema.

\subsubsection{0s instrumentos: diário ou caderno} de campo

Como o método fenomenológico não se preocupa em compreender os aspectos subjetivos do observador e em mostrar a realidade como ela é, é importante que 0 pesquisador mantenha um registro que permita fazer inferências na hora de interpretar 0 material colhido. 0 procedimento remete à antropologia, onde desde 0 início o caderno de campo servia para registrar o dia a dia da coleta de informações (TRAVANCAS, 2005).

\subsubsection{A postura do pesquisador}

\section{fenomenológico}

"Não são permitidas pela fenomenologia nem referências explícitas, nem crenças assumidas sobre objetos, fatos, propriedades ou leis que, de algum modo, transcendem a consciência." Caberia, portanto, "a descrição dessas essências no modo como elas aparecem à intuição intelectual do fenomenólogo que adotou uma posição neutra sobre o estatuto do mundo exterior." (SANTAELLA, 2012, p. 15).

\subsubsection{Quarto passo: a interpretação}

\section{0 método fenomenológico parece ser mais} adequado para situações rotineiras, onde se busca a imersão no cotidiano de indivíduos ou grupos. Como não pretende "ensacar" a realidade em formas teórico-metodológicas estabelecidas a priori, é o mergulho na realidade que produzirá estudos aprofundados e originais.

\subsubsection{Quinto passo: a redação}

Mesmo com o emprego do discurso científico, não se justifica, na área de Comunicação, artigos 
mal redigidos. Não se fala aqui apenas de erros ortográficos, mas se espera de um pesquisador da área uma escritura elegante, que respeite os cânones de um bom artigo, mas que também proporcione uma leitura envolvente.

\subsubsection{Sexto passo: o retorno aos participantes da pesquisa.}

A apresentação dos resultados do estudo aos indivíduos ou à comunidade consultada deveria fazer parte dos protocolos científicos. A devolução do conhecimento pode reforçar a autoestima dos participantes da pesquisa, ampliando o conhecimento pessoal, social e da realidade que os cerca.

\subsubsection{Sétimo passo: o compartilhamento com a comunidade científica}

Uma vez que não se trata de um método hegemônico em Comunicação, é essencial que o pesquisador esteja embasado, do ponto de vista teórico-metodológico, para justificar seus resultados em eventos e, posteriormente, publicações científicas.

\section{Reflexões sobre um estudo que} emprega o método fenomenológico em Comunicação

Tecemos considerações sobre uma pesquisa que usa 0 método fenomenológico apresentada no Grupo de Trabalho de Imagem e imaginários midiáticos, durante o XXII Encontro Anual da Compós, a Associação Nacional dos Programas de Pós-Graduação em Comunicação, realizado na Universidade Federal da Bahia no período de 4 a 7 de junho de 2013. Trata-se de $A$ formação das imagens do feminino na cosmologia da umbanda e sua manifestação no imaginário brasileiro, de autoria de Florence Marie Dravet. Dravet é doutora em Ciências da Linguagem, com pós-doutorado em Comunicação, atuando como professora do Mestrado em Comunicação da Universidade Católica de Brasília.

Embora o método não seja mencionado entre as palavras-chave (Comunicação, feminino, imaginário, umbanda e mito), ele é inserido explicitamente no resumo, que descreve 0 método: "Nossa metodologia fenomenológica e poética recorre à observação, descrição e interpretação tanto dos mitos narrados como da ritualística praticada e da vivência dos próprios médiuns participantes do processo.". Finalmente, 0 resumo aborda os achados da pesquisa. As considerações que se seguem usam como chave os sete passos alinhavados nesta pesquisa como proposta para o uso da fenomenologia como método em Comunicação.

\subsection{Revisões de literatura}

Do total de nove títulos da bibliografia, quatro referem-se à abordagem fenomenológica (CRITELLI, 1996; FLUSSER, 2005; HEIDEGGER, 1994; HUSSERL, 1965). 


\subsection{A descrição dos procedimentos metodológicos}

Dravet explicita o método, usando referenciais teóricos para embasar a escolha:

Nosso método de pesquisa é fenomenológico e poético. Procedemos à observação, compreensão e interpretação do observado, porque nosso objeto é parte do mundo vivido e, enquanto vivência, não se presta a nenhum outro tipo de análise científica. Observamos a realidade do fenômeno comunicacional de coordenação do feminino dentro das relações universais e humanas, psicológicas e sociais no âmbito do terreiro de Umbanda como fenômeno vivido e não como algo idealizado. (DRAVET, 2013, p. 4).

A pesquisadora apresenta, a partir do idealizador da fenomenologia, uma chave interessante para a compreensão do método: a de que ele não busca a explicação do fenômeno, mas sim mostrá-lo, descrevê-lo (DRAVET, 2013). Com isto, deixa-se ao leitor a possibilidade de fazer as inferências a partir da perspectiva dele.

\subsection{A entrada no campo e a seleção das fontes}

Dravet (2013, p. 4) registra, de forma concisa, seu processo de imersão no campo:

[...] a abordagem fenomenológica consistiu em, a partir do levantamento dos mitos e das entidades relacionadas ao feminino na ritualística e na liturgia da Umbanda, dentro da estrutura de um terreiro, interrogar os participantes acerca de sua vivência daqueles mitos e daquelas entidades, além de observá-los em situação.
As técnicas escolhidas são referenciadas de forma implícita. Podemos deduzir que recorreuse à observação participante ("observá-los em situação) e à entrevista aprofundada ("interrogar os participantes acerca de sua vivência daqueles mitos e daquelas entidades"). Não há referências sobre como foi feito 0 registro das informações.

\subsection{A interpretação}

Apesar da intenção de descrever o fenômeno, sem explicá-lo, em dado momento da interpretação Dravet (2013, p. 10) recorre a uma espécie de categorização das deusas:

[...] Veremos aqui que os poderes guardados e simbolizados pelos Orixás femininos se sintetizam em poder matricial original (Nanã), poder selvagem e guerreiro (Obá e Yansã), poder de geração (Yemanjá e 0xum), poder de sedução (Oxum e Yansã) e poder mágico (Ewá).

Contudo, ela não fica presa na teia

reducionista, passando a construir com estas características, como num mosaico, as múltiplas faces do feminino.

De forma implícita, sem citar nomes, estabelece a ponte entre suas observações e as entrevistas realizadas para relacionar as filhas e os filhos de santo dos Orixás femininos como aparições do feminino oculto no mistério. "Interrogamos os adeptos do terreiro e através deles pudemos identificar como se manifestam as forças do feminino dentro de cada um deles 


\subsection{A redação}

0 texto, escrito a partir da premissa da poética, faz jus à escolha textual:

0 grande arquétipo da mulher brasileira é 0 da sensualidade e da beleza. Oxum e Yansã simbolizam esse aspecto da feminilidade. Nos mitos, todos os Orixás são apaixonados por elas. Ambas são belas, mas não pelas mesmas razões. Oxum porta a beleza e a graça da feminilidade que ama, gera e cuida. Yansã possui a beleza altiva e guerreira do movimento e do impulso que conduz à ação (DRAVET, 2013: 13).

Ressalta-se a frase que fecha este parágrafo, que exprime a sensibilidade da autora: "[...] os conceitos se desdobram e dão lugar a fragmentos de complexidade, aparições de uma realidade complexa cuja totalidade se mantém oculta." (DRAVET, 2013, p. 13).

\subsection{0 retorno aos participantes e o compartilhamento com a comunidade científica}

0 artigo não deixa claro se houve um retorno aos participantes de pesquisa. Contudo, a apresentação à comunidade científica foi feita no GT Imagem e Imaginários, da Compós, onde foi acolhido com interesse por parte dos pesquisadores.

\section{Considerações finais}

Entendemos que quase um século após ter sido idealizada por Husserl, o uso do método fenomenológico nos estudos em Comunicação ainda faz sentido, uma vez que talvez uma parte da comunidade científica contemporânea pode estar demasiadamente preocupada em encaixar a realidade nos seus pressupostos teóricos, 0 que poderia estar relegando a observação dos fenômenos a um segundo plano. Pode estar, igualmente, projetando exageradamente sua visão de mundo sobre 0 universo observado, causando vieses nos resultados. A neutralidade do pesquisador pode ser utópica, mas ainda assim a atenção na experiência pode resgatar o frescor dos estudos e contribuir com resultados originais, uma vez que muitas pesquisas estão se tornando demasiado descoladas do mundo real.

Talvez a reflexão mais importante é a de que qualquer método apresenta prós e contras. 0 pesquisador deve, sempre, estudar bem o método, porém sem ficar tão preso às normas de conduta metodológicas que, como na fábula indiana, se atenha de tal forma às partes - tromba com uma mangueira, cauda com ponta peluda como uma vassoura, pata grossa como um tronco -, que se esqueça de perceber 0 todo: 0 elefante.

\section{Referências}

AMÉLIO, A.; MARTINEZ, M. Para viver um grande amor. São Paulo: Gente, 2005. v. 1. 168p .

ARANTES, P. Mídia, gestos e sociedade: diálogos entre Vilém Flusser e Fred Forest. Disponível em < http://www.flusserstudies.net/sites/www.flusserstudies. net/files/media/attachments/arantes-gestos-sociedade. pdf > Acesso em: 17 jan. 2014.

CRITELLI, D. M. A analítica do sentido: uma 
aproximação e interpretação da real orientação fenomenológica. São Paulo: Educ: Brasiliense, 1996.

DEMO, P. Metodologia científica em ciências sociais. 3. ed. São Paulo: Atlas, 1995.

DRAVET, F. M. A formação das imagens do feminino na cosmologia da umbanda e sua manifestação no imaginário brasileiro. In: ENCONTRO ANUAL DA COMPÓS, 22., 2013, Salvador. Anais... Salvador: Compós, 2013. Disponível em: < http://encontro2013. compos.org.br/anais/imagem-e-imaginariosmidiaticos > . Acesso em: 13 jan 2014.

FLUSSER, V. Da Ficção. 0 Diário de Ribeirão Preto, São Paulo, 26 ago. 1966. Disponível em: < http://www. pgletras.uerj.br/matraga/matraga13/matraga13flusser. pdf > Acesso em: 19 jan. 2014.

FLUSSER, V. Fenomenologia do brasileiro. Organização Gustavo Bernardo. Rio de Janeiro: Universidade do Estado do Rio de Janeiro, 1998.

FLUSSER, V. Les Gestes. Paris : HC-D’Arts, 1999.

FLUSSER, V. Língua e realidade. São Paulo:

Annablume, 2005.

FLUSSER, V. Ficções Filosóficas. São Paulo: Edusp, 1998a.

GIL, A. C. Métodos e técnicas de pesquisa social. 5. ed. São Paulo: Atlas, 1999.

HEIDEGGER. Serenidad. Barcelona: Ediciones del Serbal, 1994.

HUSSERL, E. Ideias para uma fenomenologia pura e para uma filosofia fenomenológica: introdução geral à fenomenologia pura. 4. ed. São Paulo: Idéias \& Letras, 2006.

HUSSERL, E. A crise da humanidade européia e a filosofia. Introdução e traduçao Urbano Zilles. 2 ed. Porto Alegre: ECUPUCRS, 2002.

HUSSERL, E. A filosofia como ciência do rigor. Coimbra: Atlântica, 1965.
HUSSERL, E.; PANZER, U. Investigações

lógicas: investigações para a fenomenologia e a teoria do conhecimento. Rio de Janeiro: Forense Universitária, 2012.

KRAMER, M. Breakable Rules for Literary Journalists. In: SIMS, N.; KRAMER, M. Literary Journalism: A New Collection of the Best American Nonfiction. Nova York: Ballantine Books, 1995. p. 21-34.

KÜNSCH, D. A. Teoria compreensiva da comunição. In: KÜNSCH, D. A.; BARROS, L. M. de (Org.).

Comunicação. Saber, Arte ou Ciência: questões de teoria e epistemologia. São Paulo: Plêiade, 2008. p. $173-195$.

LEFEBVRE, H. El existencialismo. Buenos Aires: Lautaro, 1948.

LIMA, E. P. Páginas ampliadas: o livro-reportagem como extensão do jornalismo e da literatura. São Paulo: Manole, 2009.

LOPES, M. I. V. Pesquisa em comunicação. 7. ed. São Paulo: Loyola, 2003.

MARTINEZ, M. Jornada do herói: estrutura narrativa mítica na construção de histórias de vida em jornalismo. São Paulo: Annablume: Fapesp, 2008. 282 p.

MEDINA, C. de A. Entrevista: o diálogo possível. São Paulo: Ática, 1990.

MERLEAU-PONTY, M. Fenomenologia da percepção. Tradução Carlos Alberto Ribeiro de Moura. 2. ed. São Paulo: Martins Fontes, 1999.

PERUZZ0, C. M. K. Observação participante e pesquisaação. In: DUARTE, J.; BARROS, A. Métodos e técnicas de pesquisa em comunicação. São Paulo: Atlas, 2005. p. $125-145$.

SANTAELLA, L. Percepção: fenomenologia, ecologia, semiótica. São Paulo: Cengage Learning, 2012.

TRAVANCAS, I. Fazendo etnografia no mundo da comunicação. In: DUARTE, J.; BARROS, A. Métodos e 
técnicas de pesquisa em comunicação. São Paulo:

Atlas, 2005. p. 98-109.

TRIVIÑOS, A. N. S. Introdução à pesquisa em

ciências sociais. São Paulo: Atlas, 1987.

ZITKOSKI, J. J. 0 método fenomenológico de

Husserl. Porto Alegre: EDIPUCRS, 1994. 
Phenomenology: The use as a method in the Communication field

\section{Abstract}

In other areas of knowledge such as philosophy, phenomenology is understood as a theoretical proposal. In the Communication scientific community, however, there is no such consensus: phenomenology is understood as a theory and, more commonly in recent years, as a method. The point is that this ambiguity may result in an inappropriate use, since the absence of a well defined proposal may lead to questioning the results of studies that employ such method. In this context, this article aims to discuss this issue, with a brief historical survey on the phenomenology; it debates this theoretical and methodical relationship and suggests a seven step guideline to the phenomenological method. Finally, this proposed guideline is used as a key to analyze a study built with this method. The result shows that the explanation of techniques (such as in-depth interviews and participant observation) could improve the understanding of the method for Communication field users.

\section{Keywords}

Communication. Phenomenology. Theory. Methodology.

\section{Fenomenología: El uso como un método para la comunicación}

\section{Resumen}

En las áreas de conocimiento como la filosofía, la fenomenología es entendida como una propuesta teórica. Dentro de la comunidad científica de Comunicación, sin embargo, no hay tal consenso: la fenomenología se entiende bien como una teoría y, con mayor frecuencia en los últimos años, como un método. El caso es que la ambigüedad creada puede resultar en el uso generalista del tema, una vez que la ausencia de una propuesta más bien definida puede conducir a cuestionar los resultados de los estudios que emplean tales métodos. En este contexto, el presente artículo tiene como objetivo discutir este tema, con una breve reseña histórica sobre la fenomenología, con debate teórico y metódico de esta relación y sugiere una propuesta de siete pasos para el método fenomenológico. Por último, esta propuesta se utiliza como una clave para el análisis de estudio de este método, el resultado muestra que la explicación de las técnicas (tales como entrevistas en profundidad y observación participante) podría mejorar la comprensión del método en la comunidad científica en el área de la comunicación.

\section{Palabras-Clave}

Comunicación. Fenomenología. Teoría. Metodología. 


\section{Expediente}

A revista E-Compós é a publicação científica em formato eletrônico da Associação Nacional dos Programas de Pós-Graduação em Comunicação (Compós). Lançada em 2004, tem como principal finalidade difundir a produção acadêmica de pesquisadores da área de Comunicação, inseridos em instituições do Brasil e do exterior.

\section{E-COMPÓS I www.e-compos.org.br I E-ISSN 1808-2599}

Revista da Associação Nacional dos Programas

de Pós-Graduação em Comunicacão.

Brasília, v.17, n.2, mai./ago. 2014.

A identificação das edições, a partir de 2008

passa a ser volume anual com três números.

\section{CONSELHO EDITORIAL}

Afonso Albuquerque, Universidade Federal Fluminense, Brasil Alberto Carlos Augusto Klein, Universidade Estadual de Londrina, Brasil Alex Fernando Teixeira Primo, Universidade Federal do Rio Grande do Sul, Brasil Rio Grande do Sul, Brasi

Ana Gruszynski, Universidade Federal do Rio Grande do Sul, Brasil Ana Silvia Lopes Davi Médola, Universidade Estadual Paulista, Brasil André Luiz Martins Lemos, Universidade Federal da Bahia, Brasi Ângela Freire Prysthon, Universidade Federal de Pernambuco, Brasil Antônio Fausto Neto, Universidade do Vale do Rio dos Sinos, Brasil Antonio Carlos Hohlfeldt, Pontifícia Universidade Católica do Rio Grande do Sul, Brasil Antonio Roberto Chiachiri Filho, Faculdade Cásper Líbero, Brasi Arlindo Ribeiro Machado, Universidade de São Paulo, Brasil Arthur Autran Franco de Sá Neto, Universidade Federal de São Carlos, Brasil Benjamim Picado, Universidade Federal Fluminense, Brasil César Geraldo Guimarães, Universidade Federal de Minas Gerais, Brasil Cristiane Freitas Gutfreind, Pontifícia Universidade Católica do Rio Grande do Sul, Brasil Denilson Lopes, Universidade Federal do Rio de Janeiro, Brasil Denize Correa Araujo, Universidade Tuiuti do Paraná, Brasi Edilson Cazeloto, Universidade Paulista , Brasil

Eduardo Vicente, Universidade de São Paulo, Brasil Eneus Trindade, Universidade de São Paulo, Brasil Erick Felinto de Oliveira, Universidade do Estado do Rio de Janeiro, Brasi Florence Dravet, Universidade Católica de Brasília, Brasil Gelson Santana, Universidade Anhembi/Morumbi, Brasi Gilson Vieira Monteiro, Universidade Federal do Amazonas, Brasil Gislene da Silva, Universidade Federal de Santa Catarina, Brasil Guillermo Orozco Gómez, Universidad de Guadalajara Gustavo Daudt Fischer, Universidade do Vale do Rio dos Sinos, Brasil Hector Ospina, Universidad de Manizales, Colômbia Herom Vargas, Universidade Municipal de São Caetano do Sul, Brasil Ieda Tucherman, Universidade Federal do Rio de Janeiro, Brasil Inês Vitorino, Universidade Federal do Ceará, Brasil Janice Caiafa, Universidade Federal do Rio de Janeiro, Brasil Jay David Bolter, Georgia Institute of Technology Jeder Silveira Janotti Junior, Universidade Federal de Pernambuco, Brasi João Freire Filho, Universidade Federal do Rio de Janeiro, Brasil John DH Downing, University of Texas at Austin, Estados Unidos Ana Carolina Damboriarena Escosteguy, Pontifícia Universidade Católica do

José Afonso da Silva Junior, Universidade Federal de Pernambuco, Brasil José Carlos Rodrigues, Pontifícia Universidade Católica do Rio de Janeiro, Brasil José Luiz Aidar Prado, Pontifícia Universidade Católica de São Paulo, Brasil José Luiz Warren Jardim Gomes Braga, Universidade do Vale do Rio dos Sinos, Brasil Juremir Machado da Silva, Pontifícia Universidade Católica do Rio Grande do Sul, Brasil Laan Mendes Barros, Universidade Metodista de São Paulo, Brasil Lance Strate, Fordham University, USA, Estados Unidos Lorraine Leu, University of Bristol, Grã-Bretanha Lucia Leão, Pontifícia Universidade Católica de São Paulo, Brasil Luciana Panke, Universidade Federal do Paraná, Brasil Luiz Claudio Martino, Universidade de Brasília, Brasil Malena Segura Contrera, Universidade Paulista, Brasil Márcio de Vasconcellos Serelle, Pontifícia Universidade Católica de Minas Gerais, Brasil Maria Aparecida Baccega, Universidade de São Paulo e Escola Superior de Propaganda e Marketing, Brasil Maria das Graças Pinto Coelho, Universidade Federal do Rio Grande do Norte, Brasil Maria Immacolata Vassallo de Lopes, Universidade de São Paulo, Brasil Maria Luiza Martins de Mendonça, Universidade Federal de Goiás, Brasil Mauro de Souza Ventura, Universidade Estadual Paulista, Brasil Mauro Pereira Porto, Tulane University, Estados Unidos Nilda Aparecida Jacks, Universidade Federal do Rio Grande do Sul, Brasil Paulo Roberto Gibaldi Vaz, Universidade Federal do Rio de Janeiro, Brasil Potiguara Mendes Silveira Jr, Universidade Federal de Juiz de Fora, Brasil Renato Cordeiro Gomes, Pontifícia Universidade Católica do Rio de Janeiro, Brasil Robert K Logan, University of Toronto, Canadá

Ronaldo George Helal, Universidade do Estado do Rio de Janeiro, Brasil Rosana de Lima Soares, Universidade de São Paulo, Brasi Rose Melo Rocha, Escola Superior de Propaganda e Marketing, Brasil Rossana Reguillo, Instituto de Estudos Superiores do Ocidente, Mexico Rousiley Celi Moreira Maia, Universidade Federal de Minas Gerais, Brasi Sebastião Carlos de Morais Squirra, Universidade Metodista de São Paulo, Brasil Sebastião Guilherme Albano da Costa, Universidade Federal do Rio Grande do Norte, Brasil

Simone Maria Andrade Pereira de Sá, Universidade Federal Fluminense, Brasi Tiago Quiroga Fausto Neto, Universidade de Brasília, Brasil Suzete Venturelli, Universidade de Brasília, Brasil Valerio Fuenzalida Fernández, Puc-Chile, Chile Veneza Mayora Ronsini, Universidade Federal de Santa Maria, Brasil Vera Regina Veiga França, Universidade Federal de Minas Gerais, Brasil

\section{COMISSÃO EDITORIAL}

Cristiane Freitas Gutfreind I Pontifícia Universidade Católica do Rio Grande do Sul, Brasil Irene Machado I Universidade de São Paulo, Brasil

Jorge Cardoso Filho I Universidade Federal do Reconcavo da Bahia, Brasil / Universidade Federal da Bahia, Brasil

CONSULTORES AD HOC

Adriana Amaral, Universidade do Vale do Rio dos Sinos, Brasil

Alexandre Rocha da Silva, Universidade Federal do Rio Grande do Sul, Brasi Arthur Ituassu, Pontifícia Universidade Católica do Rio de Janeiro, Brasil Bruno Souza Leal, Universidade Federal de Minas Gerais, Brasil Elizabeth Bastos Duarte, Universidade Federal de Santa Maria, Brasil Francisco Paulo Jamil Marques, Universidade Federal do Ceará, Brasil Maurício Lissovsky, Universidade Federal do Rio de Janeiro, Brasil Suzana Kilpp, Universidade do Vale do Rio dos Sinos, Brasil Vander Casaqui, Escola Superior de Propaganda e Marketing, Brasil

EDIÇÃO DE TEXTO E RESUMOS I Susane Barros SECRETÁRIA EXECUTIVA I Helena Stigger EDITORAÇÃo ELETRÔNICA I Roka Estúdio
COMPÓS I www.compos.org.br

Associação Nacional dos Programas de Pós-Graduação em Comunicação

Presidente

Eduardo Morettin

Universidade de São Paulo, Brasil

eduardomorettin@usp.br

Vice-presidente

Inês Vitorino

Universidade Federal do Ceará, Brasil

ines@ufc.br

Secretária-Geral

Gislene da Silva

Universidade Federal de Santa Catarina, Brasil

gislenedasilva@gmail.com 